\title{
New Plan for Ngorongoro
}

\author{
By J. D. Lockie
}

In this review of the new management plan for the Ngorongoro Conservation Area in Tanzania, which includes the famous Crater, Dr J. D. Lockie, of the University of Edinburgh, briefly surveys the recent history of the area leading up to the plan*, which he describes as an 'enlightened and humane approach' to the problems of reconciling the conflicting interests of the Masai pastoralists, cultivators, tourists and wildlife conservationists, and an admirable basis on which to develop and conserve this remarkable area. The Pearsall Report, one of the landmarks in the recent history of Ngorongoro and commissioned by the Fauna Preservation Society, was published in ORYX, August 1957, and an account of the Area by the then Conservator, Mr Henry Fosbrooke, appeared in ORYX, December 1965.

$\mathbf{T}$

HE Ngorongoro Conservation Area in Tanzania is not only the home of Masai pastoralists and their stock, and an important source of water for adjoining lands, but also includes a world-famous wildlife spectacle in a unique scenic setting. For these reasons it is an asset nationally, and of significance internationally.

The area has a chequered history of good intentions that have come to little or nothing. In 1940, under the provisions of the Game Ordinance, the greater part of the Ngorongoro Crater and Serengeti Reserves were combined to form the Serengeti National Park. In 1948, when the boundaries were revised and the Park reconstituted under the National Parks Ordinance, the existing rights of the Masai were expressly preserved, as no conflict between the Masai and the park objectives was foreseen. But it soon became obvious that the exercise of these rights within the Serengeti National Park was irreconcilable with the concept of one use for a national park. Further discussions resulted in proposals for a park in which all the important game areas would be free from vested interests. This, however, would have meant a considerable reduction in the size of the park, since only by avoiding conflict could the single-use concept be upheld. The publication of these proposals caused great disquiet among conservationists, and prompted the Fauna Preservation Society to commission Professor Pearsall to examine the area and to make a report, which was published in ORYX August 1957.

In that year, a Committee of Enquiry, appointed to consider the existing conditions of the park and the law relating to it, recommended that the rights of the Masai in the Western Serengeti should cease; that the area to the east of the Lake Province/Northern Province boundary should be excised from the national park; that the Crater Highlands should become a special conservation area; that the Ngorongoro and Empakaai craters should have special status as nature reserves; and the Serengeti east of the

*A Management and Development Plan for the Ngorongoro Conservation Area, by H. J. Dirschl for the Ministry of Agriculture, Forests and Wildlife, Tanzania, 1966, (pp. 133, 2 appendices, 4 maps). 
proposed national park should be a Game Controlled Area. This advice, together with certain modifications proposed by the Tanganyika Government, was presented to the Legislative Council in 1958.

Then followed the Ngorongoro Conservation Area Ordinance of 1959 which set up an authority charged with conserving and developing the natural resources of the area. In 1960 the first draft of a management plan was drawn up (revised in 1962 by H. A. Fosbrooke). In 1961 an Advisory Board of conservationists and senior government officials was instituted and met twice a year to discuss the administration and management of the Conservation Area. In 1962, the Ngorongoro Conservation Unit was set up in what is now the Ministry of Agriculture, Forests and Wildlife, in the charge of a Conservator responsible to the Minister. Then followed staff - ecologist, assistant conservators for game, forests and veterinary. At this point, the Board invited Dr W. J. Eggeling, of the British Nature Conservancy, to review the 1962 management plan. Dr Eggeling insisted that it was time to stop accepting advice, good, bad and indifferent, with all the resulting changes of policy, aims of management, staff set-ups, and emendation of boundaries. The outcome of his report is the revision of this plan by Dr H. J. Dirschl.

Dr Dirschl breaks new ground by applying modern ideas on conservation and multiple use. Conservation is interpreted to mean the best use of land based on biological productivity and the relevant social and economic factors. The term multiple or integrated land-use refers to situations in which two or more forms of land-use are actively considered in the management of the same unit of land. Thus, the purpose of multiple-use management is the allocation of each land unit to the uses for which it is best suited, by reason of its biological productivity and the relevant social and economic requirements of the area; and the subsequent development of the selected land-use pattern to the fullest extent.

These are fine words, often made but less often translated into an organisation which can manage and develop an area on an integrated land-use basis. As one use grows, other uses become more difficult to practise simultaneously. But the concept of multiple use is admirably suited to the Ngorongoro Conservation Area because of the area's great variety, and it is to the credit of the late Professor Pearsall that he realised this and proposed that all the resources should be considered and developed as a harmonious whole. It is also to the credit of the first Conservator of Ngorongoro, H. A. Fosbrooke, that he pressed for suitable administrative machinery.

An example of the interrelation of resources of the Conservation Area, and the need for an integrated development, is in the relation of the Masai to the Ngorongoro Crater. The crater, rich in wildlife and superb scenery, is a major tourist attraction in East Africa, and tourism has become a main source of income for the Conservation Unit. This has led to the Unit's channelling nearly all its effort into management of the crater at the expense of developing other facets of the area. But the continued existence of the scenic attractions of the crater, on which the tourist revenue depends, can only be assured by sound management outside it. A drought soon 
brings Masai and their cattle into the crater, their traditional grazing and water reserve; this greatly increases grazing pressure on the crater floor, and may bring about undesirable changes in wildlife abundance and increase soil erosion. It is urgently necessary to eliminate the Masai's need to do this, and the only way is by developing range in other parts of the Conservation Area.

As a foundation for gradual and rational development, the plan divides the Conservation Area, into 17 separate though related landuse zones which need to be managed and developed in different ways. They are:

1 Ngorongoro Crater: should be conserved and developed entirely as a nature reserve and tourist attraction since the needs of Masai can be met elsewhere.

2 Northern Highlands Forest Reserve: originally formed for the protection of vegetation and soil in water catchments, this remains the major consideration in determining land-use here.

3 Olmoti: watershed protection from livestock, cultivation and fires.

4 Nainokanoka-Bulbul: of great grazing potential; development towards improved livestock production is indicated.

5 Loshonyokie: recommended for a pilot grassland improvement scheme.

6 Empakaai Crater: because of its vulnerability and striking beauty, should be given total protection from use by stock and tree felling and be managed as a nature reserve.

7 Enkopironi-Naiyobi: should be developed for grazing and used solely for grazing; cultivators to be moved to Endulen (see 16).

8 Makarut Mountain: should be declared a controlled area. In particular it is necessary to control the timing of burns to prevent late hot fires. Cattle to be excluded from catchments although not from the whole area.

9 Ngorongoro-Malanja-Misigiyo: intensive management to increase the grazing potential to a maximum.

10 Western Escarpment Woodlands: main function is to prevent soil erosion on steep slopes; controlled felling and wet season grazing permitted.

11 Bulbul-Sale Plains: a wet season grazing reserve.

12 Doinyoogol-Kiti Plain: an area of low development potential; its use should continue as at present as a self-contained grazing area for a small number of Masai graziers.

13 South Oldupai-Doloinya: a wet season grazing reserve for 9.

14 Oldupai-Lemuta: forms an integral part of the Serengeti Plains ecosystem since from December to May the zone is occupied by very large migratory herds of wildebeest, zebra and gazelles from the Serengeti National Park. The tourist attraction should be developed and the Masai here given the opportunity of joining the Highland Grassland improvement schemes.

15 Kakesio-Ngairish: land use should continue to be orientated towards the grazing of livestock by resident Masai.

16 Endulen Valley: should be developed for the intensive production of agricultural crops, with hunting by permit allowed.

17 Lake Eyasi Trough: should be developed for irrigated cultivation and cattle raising. 
Knowledge of the basic information needed is fragmentary and the report indicates what routine recording of weather, vegetation and animals should be done and where, and what the priorities in research are. Finally, a staff structure is outlined and the duties of senior officers clearly stated.

The Plan must be unique in East Africa in its enlightened and humane approach to the conflicting interests of pastoralists, cultivators, tourists and conservationists. It forms an admirable basis, in terms both of conservation philosophy and application, on which to develop and use to the best advantage this exceptional area of East Africa. It is to be hoped that the support and the money will be available to translate it into action and to show the world that it can be done. In this, the Public Relations Officer has a vital rôle to play; the Plan is doomed unless the people are convinced of its sound sense.

Dr Dirschl begins his report with a quotation from Charles Elton that should be pinned to the office wall of every politician, ecologist, conservationist and protectionist - indeed anyone who has anything to do with the use of land - and contemplated every day. It exemplifies a humility to the world around him and a tolerance of other living things that man, in an age of breathtaking technological achievement, would do well to adopt:

'Unless one merely thinks man was intended to be an all-conquering and sterilizing power in the world, there must be some general basis for understanding what it is best to do. This means looking for some wise principle of co-existence between man and nature, even if it be a modified kind of man and a modified kind of nature. This is what I understand by conservation.'

\section{Giraffes in West Africa}

IN West Africa giraffes have decreased considerably in numbers in the last 30 years, according to Mr D. C. D. Happold, our FPS correspondent in Nigeria. Because of the barrier of the Niger-Benue rivers to the south and the forests and mountains to the east and west, there are no giraffe at all in Guinea, Liberia, Ivory Coast, Upper Volta, Ghana, Togo, Dahomey and Southern Nigeria. North of the two rivers those that survive are nearly all in protected areas. There are practically none now in northern Nigeria, although they were fairly numerous at the turn of the century; there were still 40-50 in the Yankari National Park in 1960 when Dr Sikes worked there, but today few are reported. They appear to be commoner in the extreme east of West Africa, in North Cameroons, where some of the largest herds are in the Waza National Park; in Tchad, where the Forest Department reports that they are increasing slowly in the south and east of the country; and in the Central African Republic, where there are many protected areas but the numbers of giraffe in them are not known. In Mali there are 150-200 in the Ansongo-Menaka National Park, which was created for their protection. In all these countries where they occur giraffes are absolutely protected - on paper at least.

\section{Moving Black Rhinos}

The Kenya Game Department Capture Unit headed by Dr John King has moved 12 black rhino from an area about to be given over to agricultural settlement into the Nairobi National Park. This brings the total number of rhinos safely translocated by the Unit to 54 . 